\title{
Application Research of 3D Digital Technology in Sculpture Creation
}

\author{
Linlin $\mathrm{Shi}^{1}$ \\ ${ }^{1}$ Jingdezhen Ceramic Institute
}

\begin{abstract}
This paper analyzes the concept of 3D digital technology first and the characteristics of traditional sculpture creation forms, then expounds the main points that should be paid attention to in the application of 3D digital technology in sculpture creation, and finally makes an in-depth analysis of the advantages of introducing 3D digital technology into sculpture creation, including the improvement of creative thinking and efficiency, unlimited creative space and the ability to convert different creative techniques in the creative process. Based on the development status of sculpture creation in China, this paper explores the application of 3D digital technology in sculpture creation.
\end{abstract}

\section{INTRODUCTION}

In recent years, China's digital technology has developed rapidly, especially 3D (Three Dimension) technology. In the field of sculpture art, this technology is also introduced into the creation, and digital technology is applied to present the sculpture structure, shape and materials completely, which promotes the new development of the practical technology of sculpture creation in contemporary society. Sculpture creators should constantly think and explore the process of combining sculpture creation with 3D digital technology, so as to promote the application of 3D digital technology in sculpture creation to play a more powerful advantage.

\section{Concept Of 3D Digital Technology And ChARACTERISTICS OF TRADITIONAL SCULPTURE CREATION FORMS}

3D digital technology is based on computer technology, Internet and computer, and uses 3D tools to realize the digital operation of virtual creation, modification, improvement and analysis of models. It is the engine to promote the integration of industrialization and informationization, and it is a modern strategic tool technology widely used in industry and cultural and creative industries. Introducing 3D digital technology into the creation of sculpture art can solve the problems that traditional sculpture creation can't achieve. Because the traditional creation forms and technical methods of sculpture have formed a model form through long-term historical development, which has both advantages and limitations. Mainly can be summarized into two aspects:

\subsection{Immobilization of sculpture creation process}

Immobilization of creative flow is one of the characteristics of traditional sculpture creation form, which is not interchangeable. In the first step, the sculpture skeleton is the core form of sculpture, and the size and dynamic potential of the skeleton should be constructed according to the whole shape space of sculpture. Its construction is a primary link in the sculpture creation sequence. The materials for constructing the skeleton are mainly wood and metal materials, and the process is slow and cumbersome. Especially, the construction of the skeleton of large sculpture works is no less than the frame construction of a building. If there are problems in the postproduction process, it must be adjusted in time, or even remade, so the construction of skeleton is the most important first step in sculpture creation; The second step, mastering the potential energy and overall shape of the molded object is the part of making after the skeleton construction, which requires the creator to show the object that meets the creation standard in the process of shape molding for a certain period of time, and mold, score and carve its details; The third step, after the sculpture image is molded on the core skeleton, it should be turned over and molded by the turning technology, and finally converted into hard material sculptures. In the traditional production process of sculpture, each process plays a vital role, and the production sequence is fixed and irreversible. If the production process is reversed, the final work will not be displayed with the original creation intention.

\subsection{Sculpture creation requires high conditions for making space}

Metal, wood, sculpture table, sculpture frame and various molding materials are all the materials needed in traditional 
sculpture making methods. At the same time, the number, volume and strength of tools used are relatively large. Therefore, it is one of the characteristics of traditional sculpture making methods to require higher conditions for creative space. Sometimes, in pursuit of the firm and accurate completion of sculpture, creators also use welding and other techniques, combined with hammering and polishing, etc., so there are great requirements for the sound insulation effect of space, space height, light source lighting, dust absorption and exhaust, etc. Threedimensional is an important attribute of sculpture, and its creation process can't be limited to single-directional observation, but requires the creator to observe, try to figure out and shape the object from different angles, so as to grasp and control the work, which requires the creator to keep a certain distance from the work. Therefore, great space demand is one of the conditions that should be possessed in the traditional sculpture creation method. In addition, if the work is reproduced, the operation space and storage space are also the parts that need to be considered in the creation. To sum up, the traditional way of sculpture creation has higher requirements for the production space.

\section{KEY POINTS FOR ATTENTION IN APPLYING 3 D Digital TECHNOLOGY IN SCULPTURE Creation}

\subsection{Pay attention to the improvement of sculpture creators' own artistic accomplishment}

The construction of 3D data by 3D digital technology has many advantages in sculpture creation. In recent years, more and more works of art are integrated with new era and new technology to realize artistic expression. Threedimensional modeling, three-dimensional scanning and three-dimensional printing technologies in 3D digital technology are very compatible with the three-dimensional modeling mode of sculpture creation, so 3D digital technology has been integrated and applied in sculpture creation, and more and more methods are used. Therefore, if you want to apply 3D digital technology flexibly and skillfully in sculpture creation to create perfect works, you must constantly improve the artistic accomplishment of sculpture creators in combination with the development of the times. Make the creators fully understand the application method and process of 3D digital technology in sculpture, recognize its role and significance as a new scientific and technological means in artistic creation, and prevent the creators from focusing only on the creation mode and relying too much on network technology in the production practice. 3D digital technology is only a kind of network technology, which needs the help of virtual data created by human beings or provided by the objective world to finally present 3D modeling. Therefore, when creators adopt digital technology, they should rely on their own professional knowledge and sculpture cultivation to guide and apply 3D technology, so as to create excellent sculpture works and make 3D digital technology play its advantages as a new technology in sculpture creation.

\subsection{Reasonable and proper application of 3D digital technology in sculpture creation}

The integration and application of 3D digital technology and sculpture creation has promoted the development of sculpture art and technology. In sculpture creation, 3D digital technology mainly uses digital materials to create sculptures. If the creation of works is completely dependent on 3D digital technology, the sculptures will not have the artistic language charm and texture effect shown by the traditional way of sculpture. Although 3D digital technology has solved some problems that cannot be realized by traditional sculpture creation, the cold, monotonous and rigid digital technology is not expressive and cannot fully interpret the richness, agility and appeal of modeling and texture presented by creators in traditional ways. Therefore, the knowledge of anatomy and modeling foundation that creators need to master is still particularly important in sculpture creation with 3D digital technology. 3D digital technology is only one of the tools or means used to assist modeling creation, and reasonable and appropriate application can better serve sculptors' artistic creation.

\subsection{The use of techniques should reflect diversity}

The emergence of 3D digital technology provides a farreaching development opportunity for the content and methods of artistic creation. The traditional way of making sculpture needs to make clay manuscript model, which is troublesome to adjust and modify. Using 3D digital technology, clay manuscript can be converted into digital model, and the work can be trimmed by digital model, which reduces the trouble of clay manuscript modification, as shown in Figure 1. The modeling, dimensions and specifications of the works are directly generated in the network software, which makes the preview of the final effect of the sculpture works intuitive, simplifies the production process and improves the production quality of the sculpture works. Diversification of techniques is one of the characteristics of contemporary sculpture plastic arts. Using 3D digital technology, different expression techniques of sculpture works can be quickly designed and converted through network data, so that the creation of works reflects diversity, and the advantages of digital technology are brought into full play to solve the creation problems that cannot be realized by traditional sculpture creation methods, such as direct scanning and copying of objective objects; Adjust the switching color, light and shadow, material texture at any time; Cut, regroup, collage and so on. 


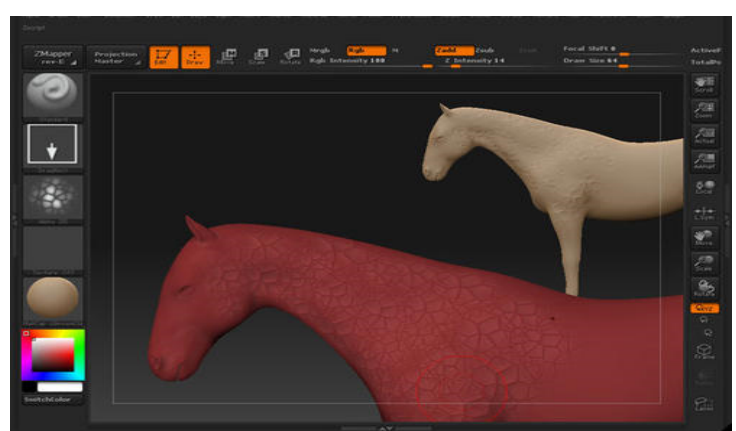

Figure 1. Digital model after clay manuscript conversion

\section{Advantages of ApPlying 3D Digital TECHNOLOGY IN SCULPTURE CREATION}

\subsection{The freedom of creating the timeline is improved}

The traditional way of sculpture creation has fixed operation steps and needs a certain amount of continuous time, so the flexibility of creation timeline is low. As a network technology, the application of 3D digital technology in sculpture creation can improve the freedom of creation timeline. By using relevant network digital software, direct 3D composition can be used to replace the process of building skeleton in traditional sculpture creation. Sculpture models that creators can think, all can be quickly and accurately built into digital models through digital software, so that the inspiration of creators can be saved in the digital software in the first time. At the same time, digital technology can be used to adjust the size, direction, layout and dynamic potential of digital models anytime and anywhere, and then complete sculpture works can be constructed by splitting, copying and connecting. Finally, 3D printing technology can be used to print the formed digital models and make solid works of any size as required, as shown in Figure 2. The application of 3D digital technology in sculpture creation reduces the production process and improves the flexibility of creation timeline.

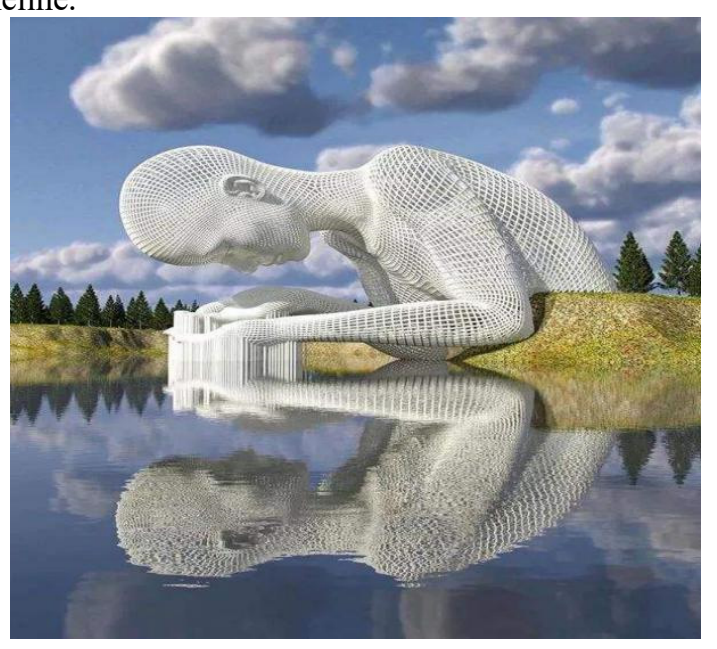

Figure 2. Sculptures presented by $3 \mathrm{D}$ printing technology

\subsection{Get rid of the shackles of creative space}

When using 3D digital technology to create sculptures, portable mobile electronic devices play an important role, thus getting rid of the constraints of creative space. Creators can design or adjust sculptures anytime and anywhere through portable computers, which improves the creative efficiency. In addition, the preservation of sculpture works created in the traditional way takes a lot of space, while 3D digital storage is to use the network to establish a database to save the digital model, and then use 3D printing technology to convert the digital model into solid works at any time, which greatly reduces the high requirements for storage space of sculpture works. 3D scanning technology can transform and save the first draft of works which are whimsical or yet to be developed, and upload it to the network database, which effectively reduces the creation cost and improves the transmission rate. 3D digital technology can also be used in combination with other network software. Through the combination of several softwares, each software can play its own functions, which can not only construct and transform large sculpture works, but also help creators to observe the model at 360 degrees, and realize unlimited preset of large space of works by using limited small workspace.

\subsection{Break through the limitations of traditional creative methods in sculpture creation}

There are many operational limitations and difficult problems in the traditional way of sculpture creation. 3D modeling and printing technology can help to complete sculpture models which cannot be realized by the traditional way of creation, such as the description and adjustment of fine details such as the combination of lines and surfaces and patterns, and the performance of some similar industrial geometric shapes which are very rational, regular and complex. Through 3D scanning technology, the objective modeling in life can be transformed into a digital model, which can be applied to the creation of sculpture works, increasing the richness of sculpture modeling and making sculpture works more practical. 3D printing technology can directly make solid modeling by using the materials that can be printed at present through model data, thus omitting the procedure of first turning over the mold and then converting the materials in the traditional manufacturing method. Finally, 3D digital technology can obtain the needs of sculpture creation, and provide relevant lighting effects and environmental effects according to the modeling needs of different sculptures, thus breaking through the limitations of traditional sculpture creation methods.

\section{CONCLUDING REMARKS}

The emergence of 3D digital technology has expanded and changed the way of sculpture creation. With the development of the times, combining digital information with art industry has become the development trend of today's society. For sculpture creators, mastering and applying new technology to help artistic creation, and not 
relying too much on technology, they should constantly improve their artistic accomplishment and grasp the development of the times, so as to make sculpture works more representative of the times and artistic creativity.

\section{REFERENCES}

1. He Peng, Ge Chunxiao. Application Research of 3D Digital Technology in Sculpture Creation[J]. Journal of Jilin Teaachers Institute of Engineering and Technology, 2019, 035(005):72-74.

2. Huang Xin. Application and Thinking of 3D Digital Technology in Sculpture Creation[D].

3. Chen Xue. Application and Research of Digital Technology in Sculpture Creation[D].

4. Cao Jingyu. Application of Digital Technology in Sculpture Creation[J]. Shanghai Vision, 2018(02):116-121.

5. Li Guanglin. Application Research of 3D Printing Technology in Modern Sculpture Creation[J]. Appreciation, 2018(11Z):65-66.

6. Ren Lizhuo. Application of 3D Printing Technology in Sculpture Creation[C]International Symposium on Interdisciplinary Collaborative Innovation and Entrepreneurship in Design. 2013.

7. Ren Lizhuo. Application of 3D Printing Technology in Sculpture Creation[C]China Academy of Art, 2013.

8. Liu $\mathrm{Xu}, \mathrm{He}$ Guanrong. Deep application of 3D printing technology in sculpture creation[J]. New Generation: Theoretical Version, 2019, 000(004): P.28-28. 